ПОВИШАВАНЕ НА БЕЗОПАСНОСТТА ЧРЕЗ МОДЕЛИРАНЕ НА СПЕЦИФИЧНИ ОПЕРАЦИИ НА МОРЕ

Валентин Василев, вВМУ "Н. Й. Вапцаров", Варна

\author{
INCREASING OF SAFETY BY MODELING OF SPECIFIC OPERATIONS AT SEA \\ Valentin Vasilev, Nikola Vaptsarov Naval Academy, Varna
}

\begin{abstract}
It is necessary wide range of activities at sea to be covered by strict requirements related to the safety. The role of different types of simulators and simulating systems becomes more important than ever. The trend is shaped by demanding requirements of International Maritime Organization (IMO) by interests of stakeholders and last, but not least it is constrained by abilities of Educational and Training Institutions all over the world. It is almost impossible without comprehensive understanding of real life processes that are essential for functioning of Maritime Transportation System. Offshore crane operations are specific and very essential for the safety at sea. For that reason specialized simulators and modeling of crane operations are vital in order to improve safety by training experienced operators, producing favorable virtual environment and making possible certification and verification of various safety plans and procedures.
\end{abstract}

Key words: offshore cranes, maritime safety, offshore industry, education and training.

\section{1. ВЪВЕДЕНИЕ}

Съвременните тенденции и изисквания към повишаване на безопасността в морския транспорт се налагат от множество фактори, определени от условия на Международната морска организация, повишаването на безопасността е свързана с интересите на собствениците и, не на последно място, от институциите, свързани с морското образование и повишаване на квалификацията на морските лица. Операциите, свързани с прехвърляне на товари на море, са характерни за функционирането на морската транспортна система и морската офшорна индустрия. Те са свързани със съществуването на риск за безопасността. Възникването на риск е характерно за специфичните дейности на море. Пример за специфични дейности, свързани с морската транспортна система и офшорната промишленост са товаро-разтоварните операции, извършвани с помощта на специализирани подемни съоръжения, които конструктивно са свързани с кораб или нефто-газодобивна платформа.

Повишаването на безопасността е възможно след моделиране на обектите и процесите. За тази цел последователно се преминава през определяне на системни изисквания в количествен аспект, в качествен аспект, а оттам и към определяне на очакваните резултати от функционирането на системата [4]. Използването на симулатор за подобряване на безопасността на море е насочено към изследване на риска, чрез проиграване на сценарии в различни условия на средата и към повишаване на квалификацията на морските лица.

\section{2. ИЗЛОЖЕНИЕ}

Откриване на формиращи се неблагоприятни условия в работната среда, които създават предпоставки за протичане на определен разрушителен процес, дава възможност за увеличаване на наличното време за реакция на оператора и съответно реализиране на про- активно въздействие върху въздействащите фактори [6]. Контрольт на случайни събития, свързани с формиране на средата на безопасност и взаимодействие на обектите и субектите на морската транспортна система или тези на офшорната промишленост, създава условия за недопускане на деструктивни процеси, т.е. осигурява се надеждно функциониране на разглежданата система при икономично изразходване на наличните ресурси.

Рискът за морската безопасност се отъждествява математически с резултата от произведението между честотата на $i$-тата реализация $\boldsymbol{F}_{i}$ на дадено случайно събитие и силата на ефектите от неговата реализация $\boldsymbol{C}_{i}$ [3, с. 196], т.е. е в сила равенството:

$$
R^{S_{i}}=F_{i} \cdot C_{i},
$$

където: $S_{i}$ - сценарий, в който е описан $i$-тия инцидент; $F_{i}$ - честота на настьпване; $C_{i}$ - сила на последствията (количествена оценка на щетите).

Честотата $F_{i}$ е статистическа величина, която служи за оценка на вероятността за сбъдване на неблагоприятно събитиеза безопасността. В сила е равенството:

$$
F_{i}=\frac{\sum_{i=1}^{m} N_{p с i}}{\sum_{j=1}^{n} N_{k o j} \Delta t_{\text {којнабл }}},
$$

където: $N_{p c i}$ - общ брой на неблагоприятни събития от $i$-тия тип; $m$ - брой типове на неблагоприятните събития; $N_{k o j}$ - брой на $j$-тия тип източници на статистически данни; $n$ - количество типове наблюдавани измерими

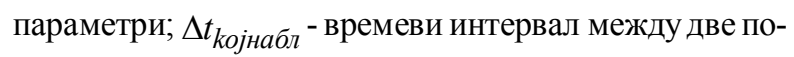
следователни наблюдения при дискретен мониторинг.

Безопасността на експлоатацията на съоръженията при осъществяване на специфична операция, например дадена товаро-разтоварна операция, се повишава с намаляване на стойността на честотата $\boldsymbol{F}_{i}$, и с 
полагане на усилия за намаляване на стойностите, заемани от величината на силата на последствията $\boldsymbol{C}_{\boldsymbol{i}}$.

Товаро-разтоварните операции на море се извършват със съоръжения с циклично действие и такива с периодично движене [1]. Машините с циклично действие имат широко приложение при обработването на различни видове товари в морската индустрия. Основните движения, които извършват са повдигане и спускане на товара. По-сложните машини извършват и странично преместване, завъртане. Конструктивните параметри и режимът на работа се определят от характера и последователността на работните движения и от особеностите на взаимодействащите обекти и спецификата на товара. При тях товаро-носещия елемент се движи периодично. Множеството от последователните операции в това движение, образуващо функционално завършен повторяем процес, се нарича работен цикъл на машината. Продължителността на работния цикъл се определя от съставните операции. Съставните операции са постоянни и променливи. Товаро-разтоварните съоръжения с периодично движение се класифицират според характера на преместването на товарите от първоначалното място до крайното местоназначение, както следва:

- За линейни премествания във вертикална равнина (двукоординатно преместване). Устройството им е възможно най-просто. Имат само един механизъм за повдигане на товара, който е твърдо или гъвкаво окачен. Примери за това са крикове, макари и др.

- За преместване по дадена повърхност (двукоординатно преместване), освен подемноспускащ механизъм имат и механизъм за странично преместване на товара. В резултат на това се създават условия товарите да се придвижват по хоризонтална повърхност. Такава повърхност е товарната палуба на офшорната платформа или горната палуба на специализиран кораб за офшорни операции [5].

- За пространствено преместване на товари (трикоординатно преместване) се използват товаро-разтоварни съоръжения с периодично движение. Подобни товаро-разтоварни съоръжения два и повече механизми.

За целите на съставянето на изисквания за разработването модел на пост за управление на специализиран кран е необходимо да се изследват основните параметри на товаро-разтоварните съоръжения. Съвкупността от количествените и качествени параметри на товаро-разтоварните съоръжения представлява техническата характеристика на съответното специализирано съоръжение. За количествени параметри се подбират скоростта на работните действия, мощността на съоръжението, собствената маса, товароподемността, геометричните характеристики на машината (физически размери, височина на повдигане и спускане) и др.

Качествените параметри включват експлоатационните качествени параметри (производителността, количеството товар, изразен в тонове кубически метри или бройки, които машината обработва за единица време при съответни условия на работа) и режимът на работа (съвкупността от фактори, характеризиращи натоварването и интензивността на използване на съоръженията в конкретни условия). Познаването на техническите параметри на товаро-разтоварните съоръжения има за цел правилно оценяване на възможностите на отделните машини при работа в конкретни условия, взаимодействието им с други специализирани съоръжения и за разработване на изискванията при експлоатация.

Корабните кранове са товарни устройства, при които товарната стрела е конструирана в един подвижен блок с механизмите за вдигане на товара и въртене. По своята конструкция крановете биват подвижни и неподвижни [8].

Неподвижните въртящи се кранове са с неподвижна и въртяща се колона. Имат по-малко тегло. Монтират се на палубите по дължината на диаметралната равнина на кораба, между два товарни люка, които обслужват и работят на двата борда. Ђгълът на завъртане обикновено е от $20^{\circ}$ до $120^{\circ}$, а може и да е неограничен. Кранът има три основни механизма: за вдигане на товари, въртене на стрелата, механизъм за изменение на обсега й. Неподвижният елемент, който не влиза във въртенето на крана е неподвижно свързан с опорна колона достигаща до долната палуба. Механизмът за въртене, както и останалите механизми са монтирани на платформа, закрепена към въртяща колона (балер). Неподвижният въртящ се кран с подвижна колона се поставя на усилена площадка от палубата. Кранът се състои от неподвижна колона и подвижна част. Неподвижната колона е монтирана на горна палуба или е закрепена за долна палуба. Подвижната част на крана се състои от кабина, механизми и електрообзавеждане, монтирани на платформа. Кранът има механизми за повдигане на товара, изменение на обсега на стрелата и развъртане на крана, които могат да работят едновременно. Изменението на обсега на стрелата се извършва с или без товар на куката. Стрелата без товар може да бъде спусната в хоризонтално положение върху поставка и укрепена за повече стабилност при изменение на стойностите на ьглите на крен и диферент. Управлението на механизмите на крана се осъществява от кабината или от подвижен пост за управление. Механизмите на електрическите кранове се снабдяват с автоматични електромагнитни спирачки затворен тип с кратни изключватели. Отделни корабни кранове с малка товароподемност се окомплектоват с ръчен привод. Голямо приложение имат крановете от електродинамичен тип. Те са с въртяща се платформа с надстройка с механизми за задвижване и кабина за управление, към която лагерува стрелата. Вдигането и спускането на шкентела и изменението на обсега на стрелата се извършва чрез хидравлични рудани ${ }^{1}$. Въртенето на крана става чрез хидродвигател.

\footnotetext{
${ }^{1}$ Специално устройство, което притежава въртящи се около ос елементи, предназначено за боравене с въжета или стоманени проволки - Бел. авт.
} 
Подвижните въртящи се кранове служат за осигуряване на товарната обработка в трюмове. Преместването на крановете се извършва надлъжно по бордовете и люковете или напречно на борда. Крановете се монтират на подвижен цилиндричен фундамент върху количка на релсов път. Количката се закрепва към релсите със специални хващащи устройства.

Корабните кранове са по-съвършени, по-компактни, заемат по-малка площ, имат постоянна готовност за работа, работят с различни товаро-захващащи механизми и създават по-малко шум. Недостатъкът им е, че имат затруднена експлоатация при вълнение, работят при крен до $5^{\circ}$, имат по-малка товароподемност, по-висока себестойност, по-сложна конструкция, изискваща комплексно обслужване. Употребата на люковите закрития с механическо задвижване на корабите, увеличаване площта на закритието на хамбарите и механизациите на товаро-разтоварните операции съкращават престоя на корабите в пристанище.

Развитието на офшорната промишленост води до необходимост от снабдяване на корабите и офшорните съоръжения и платформи с гориво, прясна вода, специални товари, детайли за попьлване на материално техническото снабдяване и ремонт. За тази цел са създадени специални кораби или се монтират специални устройства и съоръжения на съществуващите кораби.

Устройствата намират приложение при полагането на дълбоководна тръба, или на специализиран офшорен кораб - кораб за снабдяване на офшорна платформа (Platform Supply Vessel - PSV), буксир за снабдяване и работа с котвите (Anchor Handling Tug Supply - AHTS), кораб за осигуряване на изграждането на офшорен обект (Construction Support Vessel - CSV), водолазен кораб (DSV), кораб за настаняване на персонал (Accommodation Vessel), кораб-кран (Crane Vessel), дежурен кораб по безопасността (Offshore Barges and Safety Standby Vessels - SSBV) [7].

Определянето на изискванията към създаване на модел на пост за управление на специализиран кран върху включва:

- определяне на необходимите съставни елементи на модела, т.е. определяне на системата в структурен аспект;

- разработване на списък на съставни подсистеми с преки и косвени взаимни връзки между техните елементи, и съответно определяне на желаните свойства на системата, т.е. определяне на системата във функционален аспект и аспект свойства;

- определяне на ограничения при реализиране на модела и необходимите дисциплиниращи условия;

- определяне на входовете и изходите на проектираната система и взаимодействието на модела на пост за управление с околната среда и взаимодействащите модели;

- определяне на минимални изисквания към възможности за контрол на действията на обучаемия.

Определянето на изисквания в структурен аспект показва, че елементите са свързани с извършването на началните и крайните операции на товарните процеси. Процесите се състоят от действия по захващане или закачане, и действията по освобождаване, т.е. откачане и отвързване на товара. Моделираният пост трябва да притежава джойстик, индикатори и средства за мониторинг на тези операции, извършвани със самостоятелни товаро-захващащи механизми. Те отговарят на конструктивни и експлоатационни изисквания, които произтичат от тяхното предназначение.

Конструктивните изисквания са свързани с простотата в устройството на елементите на поста, устойчивост на износване на частите на отделните модули. Освен това, важно изискване е достигане на възможно най-малка маса на частите на елементите и модулите. Изискванията за еноргономичност дават варианти за композиране на отделните модули, така че да се създаде удобство в управлението на сензорите на поста и осигури добра видимост към товара и мястото на извършваните операции. Изграждането на поста на модулния принцип позволява лесна и бърза пренастройка на елементите, в съответствие с измененията в условията на средата и изискванията на оператора (обучаемия).

Към експлоатационни изисквания спадат минимален интервал от време, необходимо от подаването на управляващото въздействие от оператора за захващане или освобождаване на товара до момента на изпълняване на командата. Изискванията към безопасността при работа е водеща [2].

Задаването на определеност на системата във функционален аспект прави възможно определянето на необходимите елементи, създаване на взаимни връзки и отношения за удовлетворят на изискванията за управление на процесите, свързани със специфичната дейност на товаро-разтоварните съоръжения в офшорната промишленост. Определянето на необходимите управляващи въздействия е възможно да бъде осъществено чрез създаването на еталон. Еталонът е целесъобразно да бъде изготвен като модел на системата и е възможно да съществува във варианти за основни състояния на системата при зададени условия на средата и взаимодействащи обекти:

- Използване на кран, позициониран на офшорна платформа и специализиран кораб за офшорни операции.

- Използване на кран, позициониран на брега и обслужващ застанал в пристанището специализиран кораб за офшорни операции.

Еталонът е отражение на въздействията на целевата технология в подбран момент върху съставните елементи, връзките и отношенията между елементите. Задаването на изисквания към система във функционален аспект при различни условия на средата дава възможност за определянето й в структурен аспект при адаптацията към възникващи външни и вътрешни изменения.

Функционирането на системата се осъществява в различни условия. Специфично при използването на модела на пост за управление на специализиран кран 
е изискването за прецизност на операциите (точност на изпълнението и недопускане на повреждане на оборудването), спазване на мерките за безопасност, извършване на зададен брой операции за еденица време и др. Това налага създаване на списьк с приоритезиране на симулираните дейности във виртуалния симулатор по видове критерии за оценка.

Моделът на пост за управление на специализиран кран трябва да отговаря на изисквания, свързани с извършване на дейност, изпълнение на анализ и оценка, в рамките на определен период от време. Степента, в която определен достигнат резултат от дейността на оператора (обучаемия) влияе върху достигането на поставената крайна цел, се оценява с предварително зададени критерии за допустимост, чрез измерване на показатели. Показателите приемат стойности в определен интервал. Модельт трябва да отговаря на изисквания за осигуряване на съществуваща гранична област на стойности на тези критерий, в която е възможно да се извърши отчитане на преходни стойности. В тази гранична област се извършва преминаване от допустима в недопустима степен по отношение на извършването на предварително подбрана планирана в конкретен сценарий специализирана дейност.

Адаптирането на управленското решение за подбор на разработени специализирани дейности по товарене и разтоварване към измененията на средата се постига чрез:

- поддържане на непрекъснатост на мониторинг на околната среда чрез определяне на необходимата дискретност на измерване на индикаторите;

- поддържане на непрекъснатост на процеса на управление на въздействията върху присъстващите обекти в средата;

- адаптиране на управленските решения към измененията в средата чрез изпълнение на итерации;

- определяне и спазване на стандартни операционни процедури, свързани с поредността на дейностите, прецизността на извършваните дейности, обема на дейността, интензивността на въздействията и др.

Определянето на изисквания към свойствата на системата повишава ефикасността на процеса на моделиране на реални технически средства и пресъздаване на тяхното използване в офшорна среда. Изискванията са свързани с общи изисквания, присъщи за виртуалните симулатори [3].

Модельт на пост за управление предоставя инструмент за анализиране на дадена сложна товаро-разтоварна система. Приложим е при изследване на поведението на динамични системи, формирани от офшорна платформа и специализиран кораб за офшорни операции. Предоставя възможност за провеждане на стохастически експерименти над даден модел или проиграване на подбрани сценарии. Натрупаната статистическа информация намира разнообразни приложения в практиката и при обучението и тренировката на оператори. Постьт за управление реализира и прави използваеми абстракциите, които са заложени в симу- лационната система в структурен, функционален и поведенчески аспект. Работата на симулатора с конкретни стойности представлява симулационен експеримент при който се създава виртуална среда за придобиване на познание и формиране на практически навици в провежданите тренировки.

Специфичните изисквания към свойствата на системата са свързани с възможност за въвеждане на сценарии, в които се пресъздават всички основни условия на средата и се решават основните типове задачи. Сценариите са приложими при проиграване на основните товаро-разтоварни дейности сьс специализиран кран, присъщи в офшорната промишленост. Освен това, моделът на пост за управление на специализиран кран трябва да осигурява задаване на управляващите въздействия кьм виртуалния модел от страна на оператора (обучаемия). Постът за управление на специализирания кран се явява медиатор, чрез който операторьт (обучаемият) навлиза във виртуалната среда. В тази виртуална среда се пресъздават специфични физически обекти, представя се тяхното взаимодействие и въздействията на основните фактори на околната среда, свързани с изпълняваната товаро-разтоварна операция на специализирания кран.

Друго важно специфично изискване към системата в аспект свойства е възможност за извършване на анализ и оценка на изпълняваните товаро-разтоварни дейности и взаимодействията с други обекти от офшорната промишленост. Необходимо е преминаване през етап на определяне на системни отношения, съвместните връзки и зависимости. Това е възможно чрез проследяване на изпълнението на мисията и оценка на достигането на целта след решаване на поставени задачи в обучението.

Свойствата на системата предоставят възможност за определяне на извършената работа в качествен и в количествен аспект, т.е. оценяване на предварително зададените дейности, нивото на подготовката на оператора (обучаемия), включително спазването на зададените стандартни операционни процедури. Спазването на мерките за безопасност при извършване на товаро-разтоварните операции - включва анализ и оценка на спазване на определени стандартни операционни процедури, с отчитане на резултатите от опазването на материалната част, инвентара, обектите на извършваната икономическа дейност (обработваните товари), която се осъществява в поста за управление.

Не на последно място трябва да бъде предвидена възможност за определяне на подготовката на оператора (обучаемия) при работа с поддържащите системи и свързаността на използвания специализиран кран с взаимодействащи системи на офшорната платформа или кораба, както и с други взаимодействащи елементи, включително по отношение на безопасността и екологията.

Изготвянето на модел на пост за управление на специализиран кран минава през определяне на изисквания към управляващите въздействия към виртуалния модел 
от страна на оператора (обучаемия). Операторът (обучаемият) се поставя в среда, която пресъздава взаимодействащи физически обекти и основни фактори на околната среда, които имат отношение към извършвана товаро-разтоварна операция с помощта на специализиран кран.

Основните взаимодействащи обекти, които трябва да се моделират са:

- Специализиран кран, предназначен за осъществяване на прехвърляне на широка гама товари и осъществяване на специфични за офшорната промишленост дейности. Разположен е на борда на офшорна нефтогазодобивна офшорна платформа или сондажна офшорна платформа (сондажен кораб).

- Офшорна нефто-газодобивна офшорна платформа, разположена в изключителната икономическа зона (открито море).

- Сондажна офшорна платформа или сондажен кораб, разположени в изключителната икономическа зона (открито море).

- Специализиран кораб за офшорни операции (Offshore Supply Vessel - OSV, Platform Supply Vessel PSV, Anchor Handling Vessel - AHV и др.).

Факторите на околната среда, които са в корелация с товаро-разтоварна операция с помощта на специализиран кран се подразделят на физико-географски и хидро-метеорологически, както следва:

- физико-географски фактори - отдалеченост до бряг, форми на бреговия релеф, цвят на водата, цвят на небето, осветеност на обектите и заобикалящата ги среда, наличие и особености на морската критична инфраструктура и други проявления на антропогенната дейност (по целесъобразност, в зависимост от сценария).

- хидро-метеорологически фактори - сила на вълнението (състояние на морската повърхност), сила на вятъра (намира се във взаимна връзка със състоянието на морската повърхност, възможност за моделиране на внезапни пориви, а бурен вятър трябва да оказва неблагоприятно въздействие върху извършваните товаро-разтоварни дейности), валежи (ръмеж, дъжд, сняг), състояние на атмосферата и хоризонтална видимост (видим хоризонт, димка, мъгла) [10].

Процесът на анализ на въздействието и оценка на извършваните товаро-разтоварни дейности и взаимодействието с обекти от офшорната газодобивна промишленост преминава през етап на определяне на критичните системни отношения на съвместните връзки и зависимости. Процесът на анализ и оценка на управлението на специализиран кран в морска среда включва, без да се ограничава само до тях, следните етапи на идентифициране на изпълнението на мисията и достигане на поставената цел:

1) Определяне на извършената работа в количествен аспект - приключване на предварително определените дейности.

2) Определяне на извършената работа в качествен аспект - включва анализ и оценка на качественото ниво на подготовката на оператора (обучаемия), включително спазването на установените стандартни операционни процедури.

3) Спазване на мерките за безопасност при извършване на товаро-разтоварните операции - включва анализ и оценка на спазването на зададените стандартни операционни процедури, с отчитане на резултатите от опазването на материалната част, инвентара, обектите на извършваната икономическа дейност (обработваните товари).

4) Определяне на подготовката на оператора (обучаемия) при работа с поддържащите системи и свързаността на използвания специализиран кран с взаимодействащи системи на офшорната платформа или кораба, както и с други елементи.

5) прилагане на управляващи въздействия и поддържане на равновесието на системата по отношение на безопасността, сигурността и екологията.

Дискретността на въздействието зависи от няколко фактора. Възможността за разкриване на условия, които са предпоставка за авария или инцидент са определящи в най-голяма степен. Своевременното разкриване изисква наблюдаване на краен брой индикатори на средата, изменението на състоянието на които е критерий за наличие на опасност. Големината на изменението е показател за силата и интензивността на ответната реакция, особено когато анализьт и съответната оценка предполагат, че фазата на проактивно въздействие е отминала, т.е. разрушителният процес е вече отключен и е възможна единствено реакция за недопускане на превръщането му в необратим. В сложни условия и при висока динамика на промяна на условията на средата е възможно прилагане на съставно управляващо въздействие. Това включва определяне на вероятността от една страна външните опасности да се проектират върху съществуващи уязвимости, а от друга да се определи вероятността уязвимостите да бъдат подложени на вътрешните опасности. Вътрешните опасности са свързани с неправилно използване на системите. Съществуват няколко аспекта. Това може да бъде свързано с пропуски и слабости в обучението, тренировките и ученията, нарушаване на периодичността на провежданите тренировки и учения, занижаване на качеството на тренировките. Занижен контрол е друга предпоставка за допускане на неправилно използване на отделни системи и създаване на условия в средата за възникване и еволюция на деструктивен процес. Небрежност, нарушаване на мерките за безопасност е друг възможен източник на неблагоприятно въздействие върху средата.

Силата на последствията $C_{i}$ може да бъде определена с помощта на модел на пост за управление на специализиран кран, в рамките на симулационна система.

Пултът за управление, монтиран на крановото съоръжение, което се развърта в хоризонталната равнина, трябва да е лесно достижим от оператора (обучаемия). Пултът включва средства за: 
- Стартиране и спиране на системата.

- Контролен пулт за скоростта на силовите приводи (електродвигателите или двигатели с вътрешно горене).

- Контролен пулт за аварийно спиране на силовите приводи.

- Контролен привод за превключване на режимите на трансмисията.

В значителна степен ергонометрията се подобрява, когато бъде предвидена конзола за дистанционно управление, включваща посочените контроли.

Всички кранове, които имат директно механично задвижване трябва да бъдат снабдени със съединител или с други ефективни средства за освобождаване на механичната енергия. Контрольт на съединителя трябва да бъде в близост до оператора на мястото за управление. Основни функции, достьпни на пулта за управление на специализиран кран са: контрол на люлеещата част на крана (Swing Control); контрол на завъртането на съоръжението по остта (Auxillary Hoist Control Auxillary); контрол на основното издигане подемника на товаро-захващащото устройство (Main Hoist Control); контрол на издигането на стрелата (Boom Hoist Control); контрол на телескопичната стрела (Boom Telescope).

Модельт на пост за управление на специализиран кран следва да пресъздава във виртуална среда реален физически обект. За целите на моделирането се вземат предвид основните параметри на товаро-разтоварните съоръжения. Съвкупността от количествените и качествени параметри на товаро-разтоварните съоръжения е своеобразна техническата характеристика на съответното специализирано съоръжение. Количествени параметри са скорост на работните действия, мощност, собствена маса, товароподемност, геометрични характеристики на машината (габаритните размери, височина на повдигане и спускане).

Качествените параметри на модела на пост за управление на специализиран кран са такива експлоатационни параметри, към които спадат производителност и режим на работа, количеството товар, който съоръжението може да обработва за единица време при дадени условия на работа.

Постьт за управление на работата трябва да обезпечава зададения режим на работа на товаро-разтоварното съоръжение. С други думи трябва да бъдат отчетени съвкупността от фактори, характеризиращи натоварването и интензивността на използване на товаро-разтоварни съоръжения в конкретни условия на обстановката. Моделът на пост за управление на специализирания кран следва да въпльщава техническите параметри на товаро-разтоварните съоръжения с цел адекватно оценяване на възможностите при работа в конкретни условия, взаимодействието им с други товаро-разтоварни съоръжения, като и за разработване изискванията при експлоатация и т. н. Осигурява възможност за управление на процесите по товарене и разтоварване, така че да се достигне до максимално използване от страна на оператора на възможностите товароподемността на съоръжението. Създаването на пост за управление на симулация на товаро-разтоварните процеси помага за оптимизиране на дейността и достигане до ниски експлоатационни разходи, отработване на мерките за безопасност, отработване на стандартните операционни процедури и опазване на товарите при маневриране.

Към поста за управление на специализиран кран трябва да се предвиди възможност да постьпва следната информация [9]:

- количество товар, пренасян с товаро-захващащия механизъм, измерено в тонове със зададена точност;

- общо количество товар, претоварен в рамките на товаро-разтоварната операция, измерена в тонове със зададена точност;

- измерената производителност за дадения период от време, измерена в мерна еденица тона за час със зададена точност;

- средна продължителност на един работен цикъл в рамките на товаро-разтоварната операция;

- общо време, изтекло от началото на тренировката (упражнението), през което се провежда фактически обучение или изпит на оператора (обучаемия);

- информация за нанесените щети, поради неспазване на стандартните операционни процедури, инструкциите за мерките за безопасност и др.

\section{3. ИЗВОДИ И ПРЕДЛОЖЕНИЯ}

За осигуряване на реалистична симулация на товаро-разтоварен процес на море е необходима работна станция, позволяваща както самостоятелна, така и интегрирана работа с други работни станции за проиграване на специфични операции във виртуална морска среда, свързани с използването на специализирани кранове и съпьтстващите товаро-разтоварни дейности в логистичните възли в осигуряващите пристанища. Трябва да бъде разположен на борда на специализиран кораб за офшорни операции (Offshore Supply Vessel OSV, Platform Supply Vessel - PSV, Anchor Handling Vessel - AHV), или на офшорна платформа, удържаща мястото си с помощта на динамично позиционираща система.

Работната станция трябва да има възможност за създаване на симулация на специализирани кранове, приложими в морската транспортна система и офшорната промишленост. За изследване на риска и съответно - за подобряване на безопасността трябва да отговаря на следните изисквания:

- Да е разположен на борда на специализиран кораб за офшорни операции - OSV, PSV, AHV и др.

- Модельт на кран трябва да притежава способност да развърта стрелата си в хоризонталната плоскост на ляво и на дясно (от $0^{\circ}$ до $180^{\circ}$, измерено в полукръгова система).

- Модельт на кран трябва да може да придвижва (да издига и да спуска) подемника (стрелата) си във вертикалната плоскост нагоре надолу, така че да е напълно функционален по изпълняваните офшорни дейности. 
- Трябва да може да се симулира преместване на товар от борда на кораба и да се записват и оценяват зададени параметри на дейността.

- Трябва да има възможност за изглед от мостика на кораба върху крана, както и от самата позиция за управление на крана.

- Възможност за симулиране на различна хидрометеорологична обстановка [10].

- Симулаторьт трябва да разполага с информационен модел на кораб (офшорен обект) с динамичнопозиционираща система, така че да е възможно удържане на позицията със зададената точност в назначено местоположение (hover position).

- Да бъде предвидена възможности за изглед, от една страна - от самата позиция за управление на крана, и от друга страна - от мостика на моделирания кораб към крана, така че изгледът да обхваща в необходимия обем извършваните дейности и създава цялостна представа за условията на обстановката с анализиране и оценяване на резултатите от работата на оператора.

- Дисплеите трябва да осигуряват реалистичност на панорамната визуализация, необходима от една страна да дава поглед на обучаемият оператор върху извършващата се специфична дейност, а от друга стра- на да осигурява на потребителя общ фон и въвеждане на даден сценарий.

\section{Л И Т Е Р А Т У Р А}

1. Дивизиев, Вл. Подемно-транспортни машини и системи. София, Техника, 1993.

2. Колев, Кирил. Управление на безопасността на морския транспорт. Варна: СТЕНО, 2012.

3. Медникаров, Боян. Защита на морския суверенитет. 1. Варна: ВВМУ "Н. Вапцаров", 2008

4. Орлоев, Никола Аm. Синтез и анализ на сложни системи. Pyce: Ру "А. Кънчев", 2003.

5. Eurasia Drilling Company: RIG fleet specifications. [Accessed 20 March 2017]. Available from:

http://www.eurasiadrilling.com/media/5 $7203 /$ ASTRA\%20Specifications.pdf

6. Maritime Security Manual: Guidance for port facilities, ports and ships, 2011. v 2.0

7. Offshore Oil and Gas Resources Sector Security Inquiry, Office of the Inspector of Transport Security, Commonwealth of Australia, 2012.

8. Specification for Offshore Pedestal Mounted Cranes, [Accessed 28 March 2017], Available from: http://www.jcbbearing.com/upload/200812/20081207194512496.pdf

9. https://www.liebherr.com/en/rou/products/maritime-cranes/ ship-cranes/ship-cranes.html, [Accessed 20 March 2017]

10. Tsvetkov, M., Ch. Alexandrov. Software simulator of marine monitoring platform, 19th International Symposium on Electrical Apparatus and Technologies, SIELA 2016, p.209-215. 